\title{
Normative Data of Corpus Callosal Morphology in a North-West Indian Population- An autopsy and MRI study
}

\author{
Gupta T, ${ }^{1}$ Singh B, ${ }^{2}$ Kapoor $K_{,}{ }^{2}$ Gupta $M,{ }^{3}$ Kochhar $S^{4}$ \\ ${ }^{1}$ Departments of Anatomy, Harvansh Singh Judge Institute of Dental Sciences and Hospital, Panjab University, ${ }^{2}$ Government \\ Medical College and Hospital, Chandigarh, ${ }^{3}$ Postgraduate Institute of Medical Education and Research,Chandigarh and \\ ${ }^{4}$ Department of Radiodiagnosis, Government Medical College and Hospital, Chandigarh
}

\section{ABSTRACT}

Introduction: Morphometric measurements of the corpus callosum (CC) are necessary to have normative values for studying sex, age and race related variations.

Methods: Morphometry of the CC was done in preserved brain specimens and in MRI scans, in adults.The measurements included parameters like length, width, height of the cc, distances between genu and fornix, genu and anterior commissure, splenium and superior colliculus, distances from the different parts of the $\mathrm{cc}$ to the nearest cortical surfaces.

Results: In the preserved brain group, the length CC was $6.98 \mathrm{~cm}$ (males) and $6.86 \mathrm{~cm}$ (females) while the corresponding values in the MRI group were $7.57 \mathrm{~cm}$ and $7.1 \mathrm{~cm}$. The height CC was $2.15 \mathrm{~cm}$ (males) and $1.92 \mathrm{~cm}$ (females) in the preserved group, and $3.27 \mathrm{~cm}$ (males) and $2.59 \mathrm{~cm}$ (females) in the MRI group. The splenial width values were $1.12 \mathrm{~cm}$ (males) and $1.01 \mathrm{~cm}$ (female) in the preserved brains while the corresponding MRI values were $1.15 \mathrm{~cm}$ and $1.17 \mathrm{~cm}$.

Conclusions: The values of different CC parameters observed were almost similar to the values reported in the other two Indian studies. However, Indian values were found to be more than the Japanese values for length, height and most of the widths of CC. The length and width of CC were found to be less than those of Caucasian population. Generation of this data will help in comparing the CC structure of different sex and ages, to study variations from the normal and may help in surgical planning.

Key Words: autopsy brains; corpus callosum; magnetic resonance imaging; morphometric data.

\section{INTRODUCTION}

Anatomy of the corpus callosum (CC) has received renewed interest in recent years due to increasing number of callosotomies being performed to treat intraventricular lesions as well as for the treatment of some forms of generalized epilepsy. ${ }^{1}$ Intraoperative callosal referencing can be made easy if some direct and readily identifiable landmarks can be found. There is therefore a need to have detailed morphometric measurements of CC available for ready reference.

Pathological changes in subcortical white matter secondary to diseases like Alzheimer's, multiple sclerosis or vascular dementia can also affect CC size and area. ${ }^{2-4}$ Morphological deviations from normal may

Correspondance:

Dr. Tulika Gupta

124-A, Sector 24-A, Chandigarh-160023, India.

Email-sktulika@yahoo.com

Phone: 0091-172 2720227

Fax: 0091-172 2748077 
Gupta et al. Normative Data of Corpus Callosal Morphology in a North-West Indian Population- An autopsy and MRI study

serve as an index for the presence and progress of various neuropathological conditions.

There have been a number of studies in the past to collect morphological data on human CC. These studies are both on autopsy specimens of brain, ${ }^{5-10}$ or in vivo magnetic resonance imaging (MRI) measurements of various CC indices and ratios. ${ }^{3,4,8,11-23}$ Most of the studies have been performed in Caucasian population. However there are very few studies, on the size and shape of CC in the Asian or Indian population. ${ }^{10,} 22$

The present study was conducted to determine the morphometric measurements of the CC in normal adult population in northwest region of India. This will give us normative data on CC morphology in the population under study and thus establish reference values for studying age, gender and racial differences. In addition, deviation from the normal parameters in various neurological diseases affecting the $\mathrm{CC}$ and relative structure can be studied.

\section{METHODS}

This study was carried out in the Department of Anatomy, Government Medical College and Hospital, Chandigarh, over a period of two years from October 2003 to September 2005. It was designed as a crosssectional descriptive study.

The study material consisted of two different groups:

A. Preserved (formalin fixed) brain specimens

B. MRI brain scans

In both the sets, adult human brains/MRI scans from age 20-60 years in both males and females were studied. The brain specimens as well as MRI scans were of people with no intracranial mass, head injury or recorded brain pathology. The same measurements were taken in both the sets. Ethical clearance was obtained from the college ethical committee. The data in each set of specimens was analysed. Values obtained were compared with each other. A statistical analysis was done using unpaired t-test.

A. Preserved brain specimens: 44 (22 males and 22 females) normal adult brains were obtained from preserved cadavers. The cadavers were preserved routinely for use in dissection hall. The gender, age and available medical history were noted from the records. Sagittal section of brain was done from front to back with the cut passing through septum pellucidum. Various callosal distances and dimensions, as mentioned below, were measured with the help of a vernier caliper. All measurements were made twice and the mean value for each parameter was recorded (Fig.1).
B. MRI scans of the brain: In this group, MRI scans of 30 adults (19 males and 11 females) were included. The scan film showing mid sagittal section of brain passing through the CC was chosen for measurement. The measurements were taken directly from MRI films with the help of a vernier caliper. The values were normalized for the full size according to the scale for each scan (Fig.2).

The following sets of measurements were taken (Figs. 3 and 4):

1. Length of corpus callosum (LC): from anterior most point of $\mathrm{CC}$ to its posterior most point.

2. Maximum width of body of corpus callosum at mid point (W).

3. Maximum width of rostrum $(\mathrm{Wr})$.

4. Maximum width of splenium (Ws).

5. Height of corpus callosum $(\mathrm{Hc})$ : A line was taken through inferior most points of rostrum and splenium. Another line parallel to this was taken through the top most point of CC. Distance between these two lines was recorded as height of CC.

6. Maximum and minimum width of body of CC (Wmax and $\mathrm{Wmi}$ )

7. Maximum width of anterior half of $\mathrm{CC}$ body (excluding genu) (WBA).

8. Maximum width of posterior half of $\mathrm{CC}$ body (excluding splenium) (WBP).

9. G-F Length: Distance between anterior edge of genu to anterior edge of columns of fornix.

10. G-C Length: Distance between anterior edge of genu to anterior edge of anterior commissure.

11. S'-Sc Length: Distance between anterior edge of splenium to superior most point of superior colliculus.

12. Shortest distance from anterior most point of CC to cortical surface (A-S).

13. Shortest distance from top most point of CC to cortical surface (T-S)

14. Shortest distance from posterior most point of CC to cortical surface (P-S)

15. Length of brain (LB): From frontal pole to occipital pole of brain in midsagittal section.

16. Distance from frontal pole of brain to anterior most point of CC (F-A).

17. Distance from occipital pole of brain to posterior most point of CC. (O-P)

\section{RATIOS}

18. AP length of CC /AP length of brain (LC/LB).

19. Splenial width / length of CC (Ws/LC). 
20. Splenial width / length of brain (Ws/LB).

21. Width of body at mid point / length of CC (W/LC).

22. Width of body at mid point / height of CC (W/ $\mathrm{HC})$.

\section{RESULTS}

A. Preserved Brains: The average length of the $\mathrm{CC}$ in males was $6.98 \mathrm{~cm}$. In females the mean length of CC was $6.86 \mathrm{~cm}$. Height of $\mathrm{CC}(\mathrm{Hc})$ in males was $2.15 \mathrm{~cm}$. while in females the corresponding values was 1.92 $\mathrm{cm}$. The maximum width of CC (Wmax) in males was found to be 0.90, while the female value for Wmax was $0.86 \mathrm{~cm}$. The splenial width was $1.12 \mathrm{~cm}$ in males and $1.01 \mathrm{~cm}$ in females.

The distance between genu and fornix (G-F) was found to be $2.44 \mathrm{~cm}$ in males; in females the corresponding value was $2.29 \mathrm{~cm}$. The distance between splenium and superior colliculus ( $\left.\mathrm{S}^{\prime}-\mathrm{Sc}\right)$ was $0.86 \mathrm{~cm}$ in males and $0.67 \mathrm{~cm}$ in females.

Various ratios calculated were the ratio of width of splenium and length of CC (Ws/Lc), maximum width of $\mathrm{CC}$ at midpoint and length of $\mathrm{CC}(\mathrm{W} / \mathrm{LC})$ etc. The ratio between length of CC and length of brain (Lc/LB) was found to be 0.45 in both sexes (Table 1 ).

B. MRI group: The length of CC was $7.57 \mathrm{~cm}$. while the corresponding value was $7.1 \mathrm{~cm}$ in females. The height of CC was found to be $3.27 \mathrm{~cm}$ in males; the female value for the height of $\mathrm{CC}$ was $2.59 \mathrm{~cm}$. The values for Wmax were $0.8 \mathrm{~cm}$ in males and $0.85 \mathrm{~cm}$ in females. The splenial width was $1.15 \mathrm{~cm}$ in males and $1.17 \mathrm{~cm}$ in females.

The distance G-F was $3.01 \mathrm{~cm}$ in males, while the G-F value in females was $2.73 \mathrm{~cm}$. S'-Sc measurement in males was 0.82 and the female value for $S^{\prime}-S c$ was $0.72 \mathrm{~cm}$.

The values for ratio Lc/LB were 0.46 in males in both the age groups while in females this ratio was 0.47 (Table 1).

\section{DISCUSSION}

Corpus callosum has been the focus of fair amount of research and debate, especially its morphology in relation to various aspects of cerebral function. In recent years, most of the available studies have been carried out on MRI scans, ${ }^{3,4,8,11-23}$ while relatively few studies are based on formalin- fixed autopsy brain specimens. $5-10$

Most of the studies of CC measurements have been performed on Caucasian samples, $3,4,7,11,15,20,21,24,25$ there are very few studies on normative data of CC in Indian population. Apart from the present study, we could come across only two Indian studies on CC measurements: one on preserved brain, ${ }^{10}$ and the other on MRI scans. ${ }^{22}$ In the study by Banka and Jit, ${ }^{10}$ the parameters studied were the mid sagittal CC area and the length of CC while Suganthy et al., ${ }^{22}$ studied the length, width of rostrum, splenium and at midpoint $\mathrm{CC}$, as well as the length of the brain. In the present study a large number of additional parameters of CC morphology as well as distances from relevant surrounding brain structures have been measured. In addition various ratios as mentioned previously have also been studied. This has yielded an extensive data to serve as a baseline for future studies.

\section{A. Preserved Brains:}

\section{Length of CC (Lc):}

In the present study the length of CC in the preserved brain group was $6.98 \mathrm{~cm}$ in males and $6.86 \mathrm{~cm}$ in females. These values are very close to those reported in the other North Indian study on formalin fixed brain specimens $(7.2 \mathrm{~cm}$ in males and $6.9 \mathrm{~cm}$ in females), 10 but less than the observed values in two studies on Caucasian brain specimens; Witelson et al., ${ }^{7}$ reported an average value of CC as $7.39 \mathrm{~cm}$ in males and 7.14 $\mathrm{cm}$ in females while Going and Dixson, ${ }^{8}$ reported the length of CC to be $7.59 \mathrm{~cm}$ males and $7.41 \mathrm{~cm}$ for females (Table 2).

\section{Splenial Width (Ws):}

In preserved brain specimens the splenial width in males in the present study $(1.12 \mathrm{~cm})$ was within $1 \mathrm{~mm}$ to that reported by Holloway et al. in all three of his population groups: Columbian $(1.07 \mathrm{~cm}), \mathrm{Mt}$. Sinai $(1.21 \mathrm{~cm})$ and Australian Aboriginal $(1.03 \mathrm{~cm})$. ${ }^{9}$ Another autopsy-based study reported splenial width of $1.14 \mathrm{~cm}$ in males. ${ }^{5}$ The values in the present study were however less than those reported for Caucasian males by Weber \& Weis $(1.72 \mathrm{~cm})$ and Witelson $(1.33$ $\mathrm{cm}){ }^{6,7}$ The splenial width in females in preserved brain group of the present study was $1.01 \mathrm{~cm}$. This was less than the values reported for females in all other autopsy based studies consisting mostly of Caucasian brain samples (Witelson, ${ }^{7}-1.27 \mathrm{~cm}$ ), (Holloway et al., 9 $1.14 \mathrm{~cm}, 1.26 \mathrm{~cm}$ and $1.17 \mathrm{~cm}$ in their three groups) and (Weber and Weiss, ${ }^{6} 1.77 \mathrm{~cm}$ ) (Table 2).

Width of CC: The width of CC in males in the preserved brain group in the present study $(0.65 \mathrm{~cm})$ was similar to that reported by Witelson among Caucasian males $(0.69 \mathrm{~cm})$. However the width $\mathrm{CC}$ in females $(0.57 \mathrm{~cm})$ in the present study was less than the values $(0.64 \mathrm{~cm})$ reported by this author (Table 2 ). ${ }^{7}$

Height of CC (Hc): 
Gupta et al. Normative Data of Corpus Callosal Morphology in a North-West Indian Population- An autopsy and MRI study

The height of $\mathrm{CC}$ in the preserved brain group was 2.03 $\mathrm{cm}$, similar to the value $(1.97 \mathrm{~cm})$ observed in another study on preserved brains by Goncalves-Ferreira et al. (Table 2). ${ }^{1}$

\section{Distances:}

The distance between the genu and fornix (G-F) was $2.37 \mathrm{~cm}$ and that between genu and anterior commissure (G-C) was $2.6 \mathrm{~cm}$ in the preserved brain group in the present study. These values were less than those reported by Goncalves Ferreira et al. (G-F: 3.15 $\mathrm{cm}, \mathrm{G}-\mathrm{C}: 3.35 \mathrm{~cm}) .{ }^{1}$ However the relative distances of G-F and G-C in relation to the CC length were almost similar in both these studies.

The distances from the frontal pole to the anterior most point of CC (F-A) and occipital pole to the posterior most point of CC (O-P) were also measured. Observed values for F-A were $3.54 \mathrm{~cm}$ and O-P was found to be 5.63 $\mathrm{cm}$. These measurements for F-A and O-P were not found in available literature except in Gray's anatomy, ${ }^{26}$ where the values cited are about $4 \mathrm{~cm}$ (F-A) and 6 $\mathrm{cm}(\mathrm{O}-\mathrm{P})$ respectively but type of brain specimens used for measurement is not mentioned. Distance between splenium and superior colliculus $\left(\mathrm{S}^{\prime}-\mathrm{Sc}\right)$ measured for the first time in this study was $0.76 \mathrm{~cm}$ in preserved brain group.

\section{Ratios:}

The values of ratio of width to length of $\mathrm{CC}$ in the preserved brain group (present study) were similar to those reported by Witelson ${ }^{7}$ in both the sexes in their autopsy study; however they were less than the values observed by Going and Dixson (Table 2). ${ }^{8}$

\section{MRI Group:}

\section{Length of CC (Lc):}

In the MRI scan group the length of CC in males $(7.57$ $\mathrm{cm}$ ) in the present study was found to be a little more than the length $(7.26 \mathrm{~cm})$ reported in another MRI based study from south India by Suganthy et al., ${ }^{22}$ $(7.26 \mathrm{~cm})$, while in females the length of $\mathrm{CC}$ was found to be similar in these two studies $17.1 \mathrm{~cm}$ in present study and $7.06 \mathrm{~cm}$ in the study on sample of South Indian population). On comparison with other MRI based studies, the length of CC measured in this study was close to that reported in Caucasian population (7.49 $\mathrm{cm}),{ }^{1}$ while it was definitely more than the observed values in two Japanese reports $7.11 \mathrm{~cm}$ and $6.96 \mathrm{~cm}$ (Table 3). ${ }^{13,23}$

\section{Splenial Width (Ws):}

The splenial width measurements in the MRI group of the present study $1.15 \mathrm{~cm}$ for males and $1.17 \mathrm{~cm}$ for females) were similar to measurements for splenial width in the south Indian study, (Suganthy et al., ${ }^{22} 1.12$ $\mathrm{cm}$ for males and $1.14 \mathrm{~cm}$ for females). These splenial width measurements were more than the values in the Japanese MRI based study, (Takeda et al., ${ }^{23} 0.99 \mathrm{~cm}$ for both males and females) but less than those reported in a Caucasian study using MRI scans, (Luders et al., ${ }^{21}$ $1.99 \mathrm{~cm}$ for males and $1.76 \mathrm{~cm}$ for females). However another MRI report on splenial width in a Caucasian population reported values of $1.07 \mathrm{~cm}$ for males and $1.15 \mathrm{~cm}$ for females which are similar to the present study (Table 3). ${ }^{12}$

\section{Width of CC:}

In the MRI group the values for width CC were a little more than those reported in south Indians. ${ }^{22}$ No comparative Caucasians MRI based values for this parameter were available.

The width of the rostrum $(1.12 \mathrm{~cm})$ in the MRI group was similar to that observed by Suganthy et al. while it was more than Japanese brains (Takeda et al. ${ }^{23}-0.99$ cm) (Table 3). ${ }^{22}$

The minimum width of $\mathrm{CC}(0.46 \mathrm{~cm})$ in the present study (MRI group) was more than that reported by Okamoto et al. $--0.3 \mathrm{~cm}$ ) while the maximum width of CC was similar in both these MRI groups $10.82 \mathrm{~cm}$ and $0.9 \mathrm{~cm}$ respectively). ${ }^{13}$

\section{Height of $\mathrm{CC}(\mathrm{Hc})$ :}

In the MRI group the height of CC in males in the present study $(3.27 \mathrm{~cm})$ was significantly more than the values observed in a Japanese population, (Takeda et al. $-2.59 \mathrm{~cm}) .{ }^{23}$ The height of $\mathrm{CC}$ in females $(2.59$ $\mathrm{cm})$ was however similar to the Japanese study (2.58 $\mathrm{cm})$. Goncalves Ferreira et al. also found the height CC to be $2.55 \mathrm{~cm}$ in the MRI group; the gender differences were not specified (Table 3 ). ${ }^{1}$

\section{DISTANCES}

In the MRI group, there was a remarkable similarity in the values of G-F and G-C between the present study and those measured by Goncalves Ferriera et al. by the MRI method. ${ }^{1}$

The distances from the frontal pole to the anterior most point of $\mathrm{CC}$ (F-A) and occipital pole to the posterior most point of $\mathrm{CC}(\mathrm{O}-\mathrm{P})$ were found to be $3.52 \mathrm{~cm}$. and $6.5 \mathrm{~cm}$. respectively. Distance between splenium and superior colliculus $\left(\mathrm{S}^{\prime}-\mathrm{Sc}\right)$ in the $\mathrm{MRI}$ group was 0.78 $\mathrm{cm}$.

Some of the values obtained in the present study (width of CC and width of splenium, in preserved brain group) were comparable to Caucasian population, ${ }^{7}$ while most of the values (length and height of $\mathrm{CC}$ and widths 
Gupta et al. Normative Data of Corpus Callosal Morphology in a North-West Indian Population- An autopsy and MRI study

of splenium and rostrum-MRI group) are more than those reported for Japanese population. ${ }^{23}$ It therefore, becomes imperative to have normative data available for various racial and other groups, for comparison with normal as well as pathological anatomy

In the present study, a large number of CC parameters, distances and ratios have been measured. In most of the studies available in the literature, relatively few CC parameters have been analysed and there is no uniformity in methodologies used. This makes a comparative analysis difficult. Many of the parameters have been measured only in the present study and therefore, comparative data was not available.

There are subtle differences in certain CC measures and ratios in different groups. The differences observed might be because of difference in racial as well as ethnic populations in different study groups, which is well documented for brain morphology. For example a study on groups of 'American-Indian', 'Black' and 'White' subjects reported that the degree of right-left asymmetry in the frontal and occipital lobes varied with race. ${ }^{27}$ The results reported by Bean suggested that the splenial area relative to the total callosal area may be larger in 'negroes' than Caucasians. ${ }^{24}$

\section{CONCLUSIONS}

The values of different CC parameters observed were almost similar to the values reported in the other two Indian studies. However, there were differences from the values documented in Caucasian and Japanese population.

This normative baseline data on CC morphology with age, gender and racial difference may also serve as an index for the presence and progress of various neuropathological conditions affecting CC. The present study has also yielded data on the various distances from various parts of the brain to the nearest point on CC which again may be useful to the neurosurgeon planning surgery through these corridors.

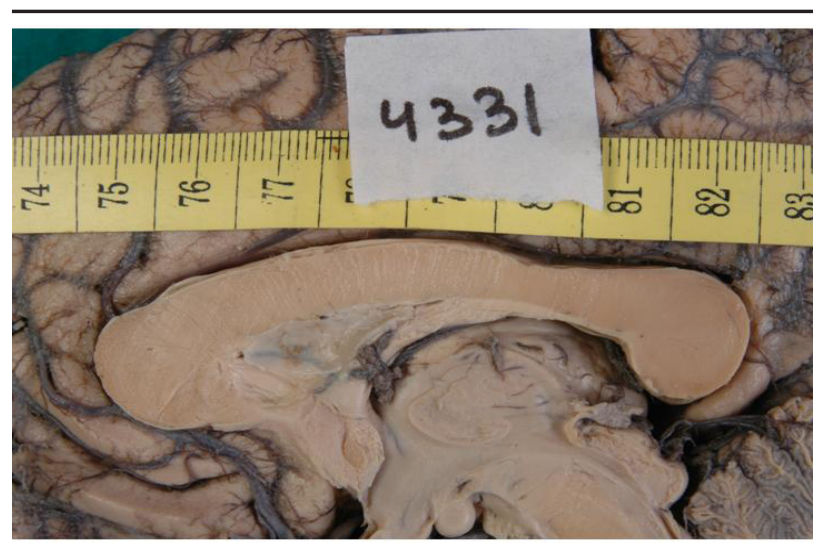

Figure 1. Mid-sagittal section of brain showing corpus callosum.

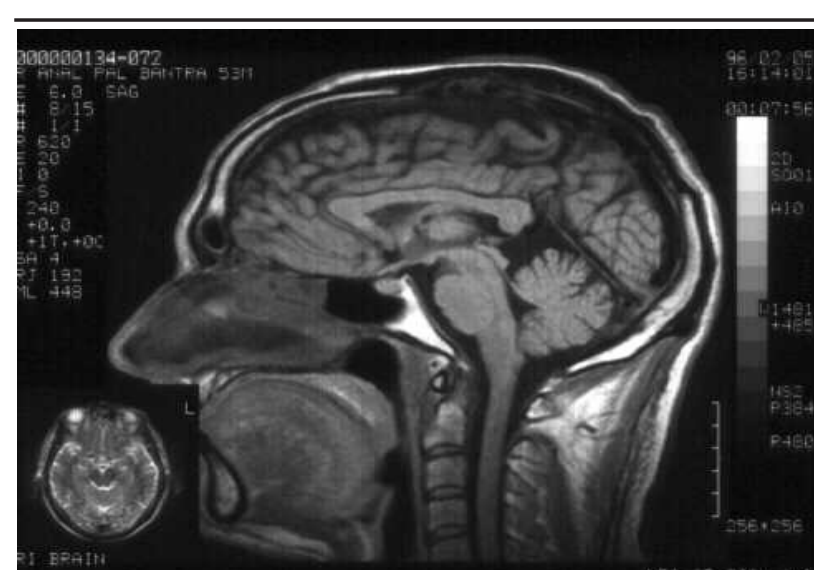

Figure 2. Corpus callosum in MRI scan, midsagittal section.
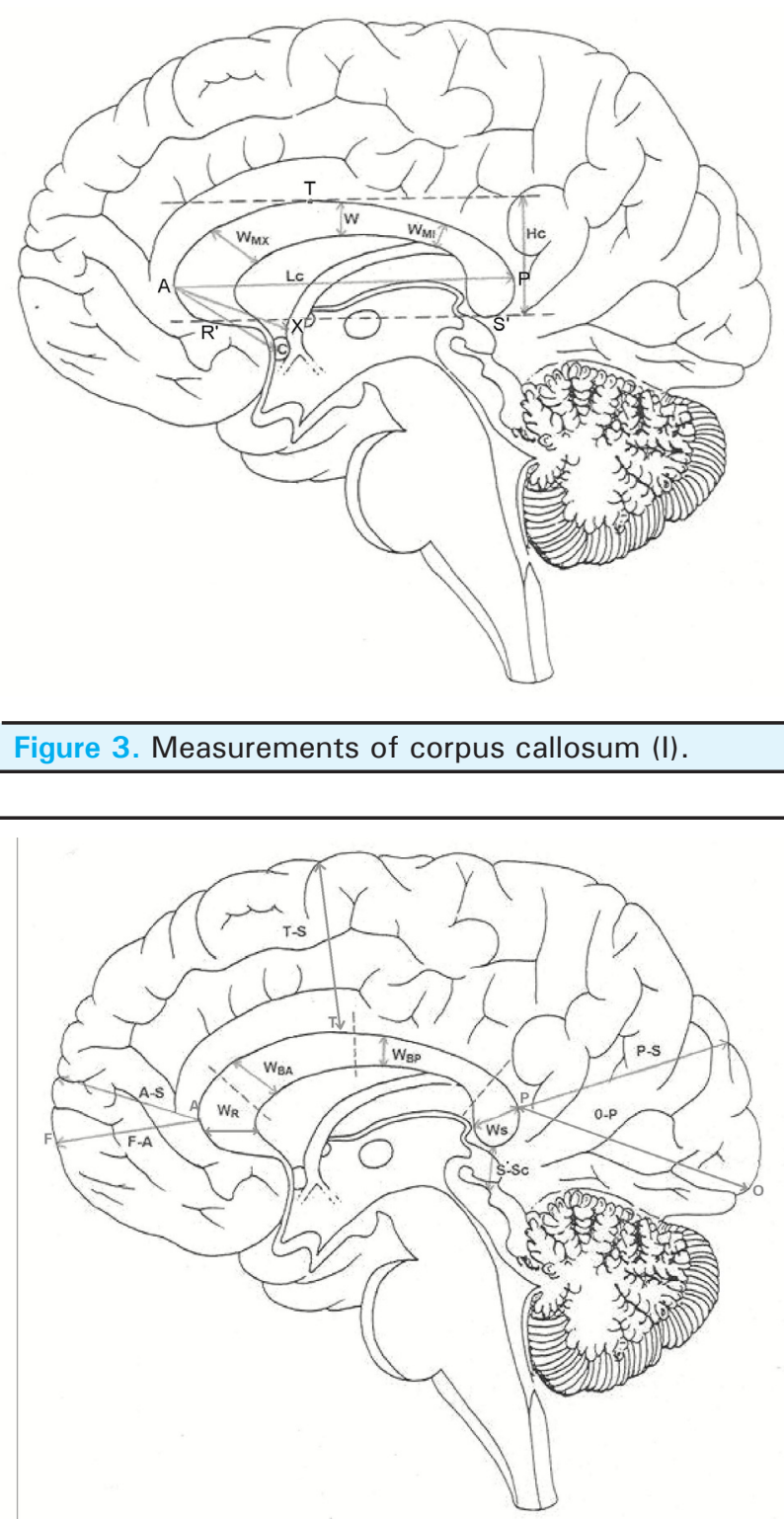

Figure 4. Measurements of corpus callosum (II). 
Gupta et al. Normative Data of Corpus Callosal Morphology in a North-West Indian Population- An autopsy and MRI study

\section{REFERENCES}

1. Goncalves- Ferreira AJ, Herculano-Carvalho M, Melancia JP, Farias JP and Gomes L. Corpus callosum: Microsurgical anatomy and MRI. Surg Radiol Anat 2001; 23: 409-414.

2. Yamanouchi H, Sugiura S, Shimada H. Loss of nerve fibers in the corpus callosum of progressive subcortical vascular encephalopathy. J Neurol 1990; 237: 39-41.

3. Weis S, Kimbacher M, Wenger E, Neuhold A. Morphometric analysis of the corpus callosum using MR: Correlation of measurement with aging in healthy individuals. Am J Neuroradiol 1993; 14: 637-645.

4. Pozzilli C, Bastianello S, Bozzao A, Pierallini A, Giubilei F, Angentino C, Bozzao L.. No differences in corpus callosum size by sex and aging. A quantitative study using magnetic resonance imaging. J Neuroimaging 1994; 4(4): 218-221.

5. de Lacoste-Utam Sing C, Holloway RL. Sexual dimorphism in the human corpus callosum. Science 216: 1431-1432.

6. Weber G, Weiss S. 1986. Morphometric analysis of the human corpus callosum fails to reveal sex related differences. J fur Hirnforsschung 1982; 27: 237-240.

7. Witelson SF. Hand and sex differences in the isthmus and genu of the human corpus callosum. A postmortem morphological study. Brain 1989; 112: 799-835.

8. Going JJ, Dixson A. Morphometry of the adult human corpus callosum: lack of sexual dimorphism. J Anat 1990; 171: 163167.

9. Holloway RL, Anderson PJ, Defendini R, Harper C. Sexual dimorphism of the human corpus callosum from three independent samples. Relative size of the corpus callosum. Am J of Phys Anthropol 1993; 92: 481-498.

10. Banka S, Jit I. Sexual dimorphism in the size of the corpus callosum .J Anat Soc of India 1996; 45: 77-85.

11. Oppenhein JS, Lee BCP, Nass R, Gazzaniga MS. No sex related differences in human corpus callosum based on magnetic resonance imagery. Ann Neurol 1987; 21: 604-606.

12. Byne W, Bleier R, Houston L. Variations in human corpus callosum do not predict gender: a study using magnetic resonance imaging. Behav Neurosci 1988; 102(2): 222-227.

13. Okamoto $\mathrm{K}$, Ito J, Tokiguchi S. The MR findings on the corpus callosum of normal young volunteers. Nippon Igaku Hoshasen Gakkai Zasshi 2003; 50(8): 954-963.

14. Allen LS, Richey MF, Chai YM, Gorski RA. Sex differences in the corpus callosum of the living human being. J Neurosci 1991; 11(4): 933-942.

15. Doraiswamy PM, Figiel GS, Husain MM, McDonald WM, Shah SA, Boyko OG, Ellinswood EH, Krishnan KRK. Aging of the human corpus callosum magnetic resonance imaging in normal volunteers. J Neuropsychiatry clin. Neurosci 1991; 3: 392-397.

16. Habib M, Gayraud D, Oliva A, Regis J, Salamon G, Khali R. Effects of handedness and sex on the morphology of the corpus callosum: A study with brain magnetic resonance imaging. Brain and cognition 1991; 16: 41-61.

17. Rauch RA, Jinkins JR. Analysis of cross sectional area measurements of the corpus callosum adjusted for brain size in male and female subjects from childhood to adult hood. Behav Brain Res 1994; 64(1-2): 65-78.

18. Salat D, Ward A, Kaye IA, Janowsky JS. Sex differences in the corpus callosum with aging. Neurobiol aging 1997; 18: 191197.

19. Bermudez P, Zatorre RJ. Sexual dimorphism in the corpus callosum: Methodological considerations in MRI morphometry. Neuroimage 2001; 13: 1121-1130.

20. Sullivan EV, Rosenbloom MJ, Desmond JE, Pfefferbaun A Sex differences in corpus callosum size: relationship to age and intracranial size. Neurobiol Aging 2001; 22: 603-611.

21. Luders E, Rex DE, Narr KL, Woods RP, Jancke L, Thompson PM, Mazziotta JC and Toga AW. Relationships between sulcal asymmetries and corpus callosum size: Gender and handedness effects. Cereb Cortex 2003; 13: 1084-1093.

22. Suganthy J, Raghuram L, Antonisamy B, Vettivel S, Madhavi C, Koshi R. Gender -and Age -related differences in the morphology of the corpus callosum. Clin Anat 2003; 16: $396-$ 403.

23. Takeda S, Hirashima Y, Ikeda H, Yamamoto H, Sugino M, Endo S. Determination of indices of the corpus callosum associated with normal aging in Japanese individuals. Neuroradiol 2003; 45(8): 513-518.

24. Bean RB. 1906. Some racial peculiarities of the Negro brain Am J Anat 5: 353-432. Cited in Witelson SF. Hand and sex differences in the isthmus and genu of the human corpus callosum. A postmortem morphological study. Brain 1989; 112: 799-835.

25. Biegonn A, Eberling JL, Richardson BC, Roos MS, Wong STS, Reed BR, Jagust WJ. Human corpus callosum in aging and Alzheimer's disease: a magnetic resonance imaging study. Neurobiol Aging 1994; 15: 393-397.

26. Standring S, Ellis H, Healy CJ, Johnson D, Williams A, Collins $\mathrm{P}$ et al editor(s). Gray's Anatomy. The Anatomical Basis of Clinical Practice. 39th ed. London: Elsevier Churchill Livingstone 2005: 411-414.

27. McShane D, Risse GL, Rubens AP. Cerebral asymmetries on CT scan in three ethnic groups. International Journal of Neuroscience 1984; 23: 69-74. 